\title{
The role of vision in determining family, small business and minority ethnic business research
}

\author{
Professor Claire Seaman and Richard Bent
}

\begin{abstract}
Family business and migration pre-date written history and yet are relatively young fields of research, which has to some extent evolved in parallel with the fields of small business research and minority ethnic entrepreneurship. In practice, however, the strands often overlap and contain common issues and challenges, this overlap provides a hinterland currently not fully explored and contextualized within research. Drawing together current research from the three fields, this chapter will highlight and conceptualize the overlaps as a working model for future analysis and highlight a number of key areas for future research. This sometime artificial distinction is especially important where research is developed into practice. The development of appropriate support systems through formal and informal networks is a key priority for communities, economies and the success of the family themselves.
\end{abstract}

\section{Keywords}

Family business, minority business, ethnic business, small business, migration

\section{Introduction}

Family business and the links between migration and enterprise pre-date written history and yet are relatively young fields of research, which have to some extent evolved in parallel with the fields of small business research and minority ethnic entrepreneurship. In practice, however, the strands often overlap and contain common issues and challenges. This overlap provides a hinterland currently not fully explored and contextualized within research. This poses something of a challenge for researchers. Whilst good research questions generally sit firmly within one theoretical framework, the overlap between different research fields can provide some of the most fruitful areas for new research and, whilst often complex, should not be ignored. The question that develops, of course, is how these inter-twined strands of research can be brought together, accepting from the outset that whilst there are overlaps there are also key differences.. If entrepreneurship is viewed as a gradual, step-by-step production of a different future, the process of business start up includes and is facilitated by an initial vision of what that future could and should look like. This envisioning of a different future and the development of a plan to achieve it is vital, but the importance of vision should not be under-estimated.

Focusing on the vision that drives the process of business creation also offers an explanation of the well-documented heterogeneity of family businesses (Dibrell and Memili, 2018). Family business research takes as its starting point an established interaction between the family and the business. Whilst this may sound obvious, it stands in very distinct contrast to the study of 'corporate' business where the focus tends to deliberately exclude family/business interaction (Dibrell and Memili, 2018). 
In contrast, small business research focusses primarily on business size and vision may be a key factor that differentiates between the established business owners who are content to run a small business and those for whom small business is but a transient point on the route to business growth. Interest in migration and entrepreneurship, in contrast, has lead to the development of a raft of small business research in distinct communities that intersects with family and small business research, and yet in many areas is considered as a separate field. In part, this may be due to the embedding of culture within the entrepreneurial processes and a focus on the importance of culture in business start-up, but there remains considerable overlap between the different fields.

The intersection between family business research, migrant business research and research published in the field of small business is marked but not fully explored and the links to the initial vision for the business may provide a useful focus for future research. Within the literature, early identification of the intersection of these three fields appears in two key papers. Writing, in part in response to the dialogue around small business revivalism in the late 1980s (Rainie, 1989; 1990; Burrows, 1990; Ritchie, 1990), Burrows (1991) speaks of the petty bourgeoisie as a group who share a common access to small-scale capital but acknowledges earlier work by Scase (1982) that speaks of a 'melange of groupings' within the petty bourgeoisie. Burrows (1991) struggles to identify where the petty bourgeoisie 'fit' into the occupationbased structures traditionally used to classify social class, for reasons evident in 1991 and probably more clearly acknowledged in the $21^{\text {st }}$ century. Occupation-based class systems tend to assume that each household has one clear 'head', whose earned income is the source of funds and thus accrued status. This poses two major problems for small business research: the first (and simplest) challenge is that in the $21^{\text {st }}$ Century, most couple or families have more than one economically-active person. Indeed, a very common pattern emerges around business start-up whereby one family member continues to earn a wage or salaried income and that income under-writes day-to-day living expenses whilst the business is set up and established to a point of profitability. The second major challenge for $21^{\text {st }}$ Century researchers is that as expected life-span has increased, small business development in the second half of life has become more common. This group - the so-called - silver-entrepreneurs join a group of small business start-ups for whom the new business per se is not the sole or even primary source of income. The history of propertyprice inflation within the UK, allied to the now disappearing but highly lucrative final salary pension schemes has created an older group of entrepreneurs with established financial security who sometimes create small businesses as an added dimension in the second half of life. Whilst these businesses are often dismissed as 'lifestyle businesses', this does them a disservice. The channeling of expertise into small business development is always dependent on life-circumstance and access to capital in a variety of forms. 
Indeed, access to capital and the mitigation of the immediate need for income in the early stages of business development would merit further research in their own right.

This confluence of personal circumstance and access to capital in a variety of forms is core to the business formation process by individuals, couples and families across all communities. Indeed, the small business revivalism observed in the UK in the 1980s was articulated as part of political discourse in response to a variety of economic and social problems. This is key because, although Burrows (1991) is talking about small business in the general community, the economic imperative that drives many small businesses exists at different times and for different reasons across the spectrum of economies, communities and families. Writing of responses to similar challenges in a different community, Ram and Holliday (1993) acknowledge quite explicitly the links between family and small firm research in their work within minority ethnic run businesses. Drawing on a sample of Asian-owned clothing manufacturing firms in the West Midlands region of the UK, their research found the 'family' to be both a resource and a constraint, but indubitably a factor. Interestingly, the work by Ram and Holliday (1993) also highlight 'negotiated paternalism' as part of the modus operandi observed within the small firm sector; a finding replicated in more recent research in a variety of communities. The policy or practice on the part of people in authority of restricting the freedom and responsibilities of those subordinate to or otherwise dependent on them in their supposed interest. Wider discussions on paternalism as the practice on the part of people in authority of restricting the freedom and responsibilities of those subordinate to or otherwise dependent on them in their supposed interest have value in the study of family and small business in all communities, but stand distinct from the debates around gender because the definition describes a pattern of behaviour rather than the gender of the individual whose behaviour is being discussed. As the fields of family business, small business and minority ethnic business have developed, so the research has tended to diverge into specialist journals and focused, targeted pieces of individual research. This chapter posits, however, that only by acknowledging this intersection can the fields be fully developed and the role that business vision plays in setting the pattern of business behaviour in different circumstances by fully explored.

\section{Family business research}

Family business is a field of research whose early development was characterized by a definitional debate that continues in some quarters to the present day. Early work by Chua et al (1999) highlighted the many operational definitions of family business being used in research and argued that a theoretical definition was important, given that the components of family involvement typically used in operational definitions are weak predictors of intentions and thus do not reliably distinguish between family and non-family businesses. This debate continues and whilst many operational definitions have been developed, the field 
has in many ways accepted this ambiguity. In their 2013 review, Xi et al used bibliometric citation analysis to analyze the field of family business research and highlighted four distinct clusters within published literature: definitions, governance in family business, competitive advantage and leadership \& management. The four clusters identified are important, not least because they are areas also of importance to the wider small and medium business world and in many ways illustrate the overlap between the fields of research. This overlap is not considered directly by Xi et al (2013), highlighting scope for future research that encompasses vision and its role in the development of strategic vision. The determinants of strategic vision and the impact of those determinants on growth trajectory may form a potential bridge between family business research, minority ethnic business research and small business research. A unifying feature across the three fields is that some businesses stay deliberately small, others aim for growth (successfully or otherwise) and a distinction remains between businesses that aim to reach the mainstream consumer and those that aim to stay within a geographic or cultural niche. Seaman et al (2015), who developed an initial framework that summarized the perceived and desired futures envisaged by different families running businesses within the Scottish Pakistani community, provide an example of these distinctions within work. Critically, all the businesses included in this research had a vision, but the nature of that vision varied widely. For some, an immediate income to support the family (sometimes with a considered view that the next generation would do 'something better') was a very clear vision focused primarily on the creation of job for the individual and sometimes a spouse. The focus by Governments on job creation in a more substantive sense should not preclude a recognition that personal job creation remains a defining small business for many individuals in different cultures and contexts.

\section{Migration and minority ethnic business research}

Migration is a vast topic, considered here in the context of the patterns of entrepreneurship and business start-up that sometimes result. The history of migration encompasses changes in world labour markets and the flow of migrants, immigrants and emigrants in response to political, social and economic circumstance. In the context of entrepreneurship, however, the key factor is that migration always encompasses change, challenge and, often, opportunity. That migration may be desired or feared is often less immediately relevant: change triggers the need to adapt and entrepreneurial behaviour often follows. Further, in Ravenstein's early modelling work, his seven laws of migration (Greenwood, 2003) highlight factors that facilitate migration but also facilitate the development of new opportunities. In particular, Ravenstein highlighted that improved infrastructure facilitates migration and that migrants travelling long distances tend to migrate to larger centers of industry or commerce. Interestingly, Ravenstein also highlighted that women are more migratory than men (Ravenstein, 1851; Greenwood and Hunt, 2003) but that women tended to migrate for relatively short distances. More recent work has highlighted important differences 
between countries from which primarily men migrate and those who tend to 'export' women (Donato, 1992; Oishi, 2005; Gabaccia et al, 2006; Immigration History Research Centre, 2015), but the link between migration and the development of new businesses remains robust.

Migration does not always result in business start-up, of course. In research that looked at the effort bargaining process of new migrant worker, Baxter-Reid (2016) comments on the demand for migrant labour as a 'hard' human resource strategy and observes a recent pattern within the EU whereby highly skilled worked from lower income countries migrate into (generally) low skilled roles. The relatively low skilled nature of many of the jobs discussed with Baxter-Reid's work is pertinent, however, as a relative paucity of personal opportunity remains one of the classic triggers for the entrepreneurial response that leads to business start-up. It also emphasizes, however, that not all migrants start businesses and thus that from a research perspective there must be factors that facilitate or encourage business start-up over and above the migration process. Business start-up, even where migration sits in the background, still depends upon the confluence of personal circumstance and access to financial or social capital or indeed a key resource. That capital usually includes, but is not limited to, financial capital. Some successful minority ethnic business communities in the UK exist where new migrants joined an establishing community, gaining access to both financial capital and a community-based social capital understanding of local markets and the mechanisms by which small business in a local area operate. This practical understanding of the manner in which small businesses operate in their local area should not be under-estimated but, conversely, the shared process of business start-up and initial development should not be taken to pre-suppose that all businesses in the community share a long-term vision. Within individual communities there are likely to be a range of business visions and further research that considers differences in the range of business vision exhibited within and between communities would be worthwhile.

The different routes forward for families running established minority ethnic businesses were highlighted in work that considered the Pakistani community in Scotland (Seaman et al, 2015). Noting that from Generation 1 , the community observed a pattern where the future was impacted upon by relative economic prosperity and indeed cultural change. Whilst the 2015 research highlighted the possible development of 'heritage businesses' with strong formal governance models, it stopped short of acknowledging that some of the businesses started within the minority ethnic community develop along a very traditional 'corporate' model to an initial public offering and beyond (Dhaliwal, 2008). Further, envisaging a 'heritage' business does not preclude individuals getting trapped in a dying business format when local conditions change and it is worth noting that some of the future for individual businesses is determined by changing market conditions rather than the plans of the business owner per se. One question that remains, however, is to 
what extent those envisaged futures are influenced by the confluence between family, ethnicity small business domain or whether the envisaged future is a reaction by the principal players to the observed success or otherwise of the business. Whilst culture may play a key role in the desire for business ownership amongst some participants, others may view a successful business start-up primarily as a platform for future development and the creation of personal and family wealth. It seems likely that within all communities a spectrum of approaches exists amongst different individuals with different valued outcomes as described in the Polish community in Leicester by Vershinina et al (2011) whose research used social and economic capital as a lens to consider entrepreneurship in well-established and more recent migrants to the UK.

\section{Small business research}

The early paragraphs of this chapter outlined the processes that facilitate business start-up and, in particular, the confluence of personal circumstance and access to capital that must exist for good ideas to become successful businesses. Somewhere within those personal (intellectual) circumstances however, there must exist a vision for what that business might look like and, usually, one or more entrepreneurial ideas. The use of the term 'entrepreneurial' may in itself be misleading, however, where the primary driver for a business is the need to create a job for the individual. This provides a link to early work in the field by Fillion (1988), who proposed that the key factors that determine small business progress are vision, the relations of the people who will make that vision happen and the capacity for anticipated learning that helps to make that vision a reality. This highlighting of vision in the strategic reality of small business is carried implicitly into much small business work and considered vital by consultants who work in the field. Cossette (2001) highlighted a new system that aimed to help small business owners and managers make their strategic vision more explicit. Based on cognitive mapping, this was billed primarily as a tool for consultants but its use in the exploration of early strategic vision and its impact on business progress in a more general sense has not been fully explored. What does seem likely, however, is that vision plays a key role in the pattern by which small businesses either remain as small businesses, are developed for sale as a going concern or, alternatively, expand to form larger family businesses or towards public ownership via an initial public offering. It is this vision - allied to, for example, access to capital to finance the vision and indeed social capital that helps with practical approaches - that could reasonably form a focus for future research that explores the intersection between research in the fields of family business, small business and minority ethnic business.

\section{Vision - the defining factor?}

When considering the manner in which businesses start, grow and develop it is important to note that all businesses start somewhere. Very often, businesses start from a very small operation, driven by one or 
many of the well-researched drivers of entrepreneurship and facilitated by the confluence of personal circumstance and access to capital outlined earlier in this chapter. Vision may, it is hypothesized, be a key factor in determining which businesses stay small, with the primary purpose of supporting an individual family whilst others grow and develop, often embracing other patterns of ownership as they develop. What remains difficult to predict is which business start-ups will follow the different possible patterns. The success or otherwise of the initial idea and/or business model may seem an obvious determining factor and, to some extent, it is. Many new businesses fail, often at considerable personal and financial cost to the individuals involved. For those that survive the initial start-up period, on-going success in the early stages is often linked to one individual and the antecedents of growth may be best studied by a consideration of the individual's characteristics. The study of the role and importance of vision in strategic planning is relatively well established in larger businesses and indeed communities (Riva and Pilotti, 2018), but rarer in new ventures and small businesses (Mohr and Berendes, 2018). The role of the vision for a business in the mind of an individual or small group (perhaps, indeed, family) is an area that merits further exploration and may play a key role in the development of greater understanding of the intersection between family business, small business and minority ethnic business. Developing our understanding in this area is especially importance because there is clear evidence that the long-term success of the business cannot in any simple sense be defined by the quality of the initial 'entrepreneurial idea'. Many very successful businesses develop from an initial idea that is good-but-not-unique and indeed the most successful business is often not the first-to-market with a new idea.

Figure 1 captures some of the commoner paths of business development and highlights the intersection between the fields of family business, small business and minority ethnic business. Crucially, of course, the central positioning of 'mainstream business' encompasses larger, perhaps multi-national business, but the routes by which the businesses reach that central point on the model are many and varied. 


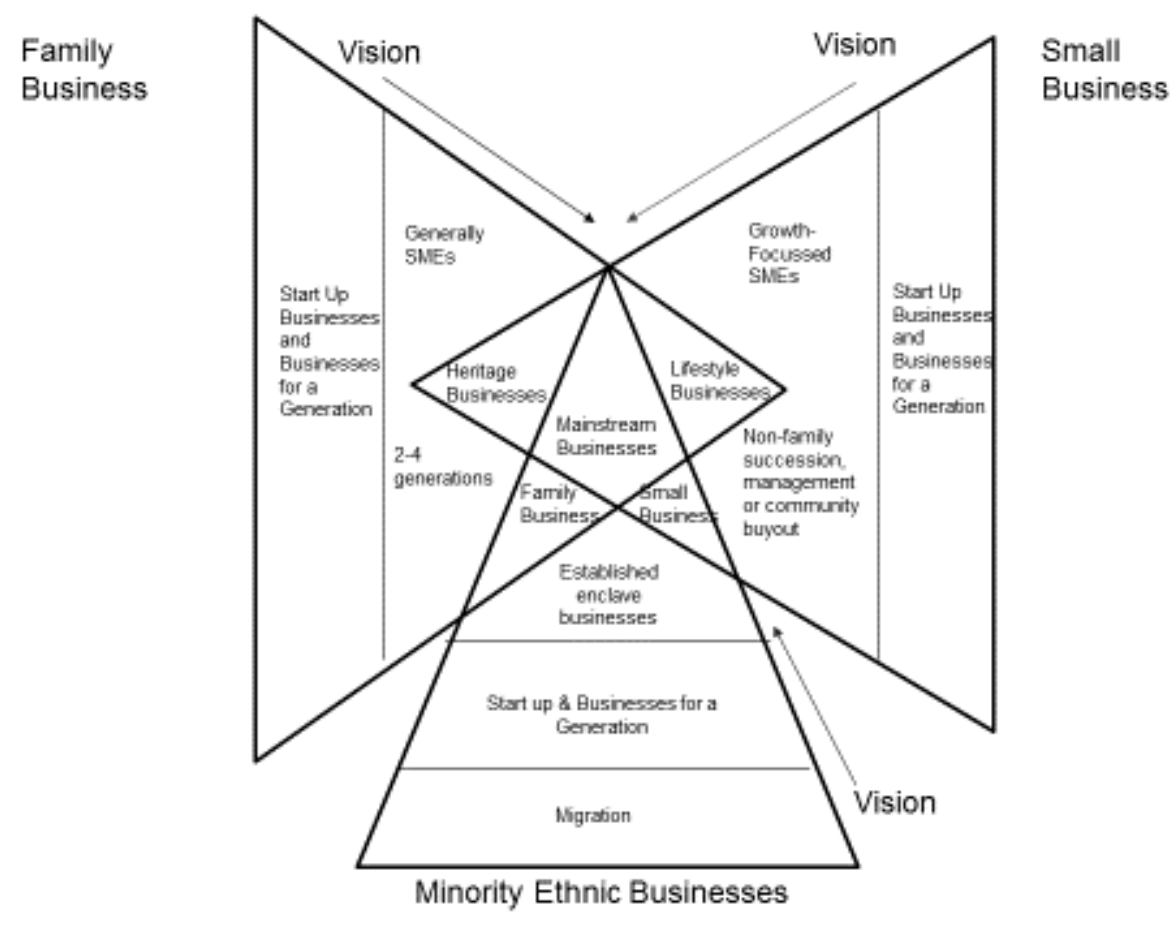

Figure 1 Synthesizing the hinterland of family business, small business and minority ethnic business research

If initial and on-going vision for the business is one of the driving factors that moves a business toward the center of the model, vision in itself merits further exploration in the context of small business start-up in diverse economies, communities and families. One of the many research challenges in this area is the acknowledged inter-twining of family (or personal) and business strategy (Fletcher, 2002; Hall, 2002). All businesses start somewhere and usually involve some level of formal or informal family support. This does not necessarily mean that the organisation is envisaged as a family business, but acknowledges start-ups where individuals are partners in the personal and business sense, those formally started by an individual but where a spouse or personal partner supports the family during the early stages and cases where parents or other relatives support a nascent business through funding or practical help (accommodation, childcare or indeed moral support). Inherent within that early stage, therefore, is an intertwining of business start-up strategy and family or personal circumstances and strategy. In many family businesses, the influence of this start-up phase leads to the classic intertwining of family and business strategy acknowledged by Hall (2002). This intertwining of family and business strategy tends to be written about within the family business literature but in practice also applies to many minority ethnic businesses whose roots lie in the migration experience and indeed some small business where the intertwining consists of personal and business strategy. The parallels between these categories should not be ignored because they illustrate a key difference between the classic study of corporations and research that considers the wider field of family, smaller and minority ethnic business. 


\section{Conclusions and future research directions}

More research to explore the synergies between these three different areas of research would certainly be useful. Exploring the synergies between the different fields of family, small and minority ethnic business would allow those which do have a particular niche distinctiveness to emerge more clearly. For example, not all family businesses are small but delineating between factors that primarily arise from the small business perspective and those that are primarily family business challenges would offer a more focused perspective for future research. Similarly, migration in itself offers a distinct perspective on entrepreneurship, employment and business start-up. However, as communities establish and enclaves form, the impact of culture, mixed embeddedness and the family on the businesses that are established evolves (Vershinina et al, 2011; Seaman et al, 2015). Future aspirations also vary widely: some families see the primary purpose of the business as a financial basis for the next generation to do 'something better'. Others view the business as the beginning of a multi-generational business or indeed as the beginning of a 'business family'. This aspect may be best documented in the minority ethnic business literature but it undoubtedly also applies to some small businesses and indeed family businesses where migration is not part of their recent history. Research from the family business field, however, indicates that some families consider the retention of a small-to-medium business under family ownership and possibly management as a key end goal in itself and this would merit further exploration $\mathrm{n}$ the context of regional economic development research. Business is inherently challenging and many of the approaches for dealing and succeeding in business are common to all types of business. It could be argued that in many of the business considered here, a lack of awareness and/or business education may preclude well-tried approaches being tried and this is an area that may be more complicated where those who might benefit from business support are relatively new to their country, region or indeed to business itself.

This chapter posits two major areas for development of future research. Larger, quantitative research that allows start-up businesses to be explored and followed on longitudinal basis would allow clusters to be viewed and explored. A second piece of longitudinal research would consider the business and personal or family vision evidenced during the start-up process and the path followed by the business over 2 or more generations, probably using qualitative methods including narrative to examine differing viewpoints amongst different individuals over time. Whilst both would be extremely long pieces of research, the developing field of family business is beginning to see longer-term structures that could support long-term data collection and on-going analysis. That the data would provide a critical insight into the intersection between business start-up and the many routes businesses follow thereafter is not really in doubt. The logistics for such an ambitious undertaking would be considerable but worthwhile. A number of other 
studies beckon that would enhance the field of research, which might reasonably be run in different communities with different levels of new-country embeddedness. Some examples ae given in Table 1.

Table 1: Future research directions

\begin{tabular}{|c|c|c|}
\hline $\begin{array}{l}\text { Research } \\
\text { direction }\end{array}$ & Topic/Main theme & Research Question(s) \\
\hline 1 & $\begin{array}{l}\text { A holistic approach to the study of } \\
\text { start-up businesses to identify and } \\
\text { explore the behaviour of those that } \\
\text { develop into family businesses }\end{array}$ & $\begin{array}{l}\text { Do nascent family businesses display distinct } \\
\text { traits during their formative years that facilitate } \\
\text { future development towards long-term ( } 3 \\
\text { generation }+ \text { ) family ownership/management }\end{array}$ \\
\hline 2 & $\begin{array}{l}\text { Community knowledge sharing } \\
\text { behaviors in established minority } \\
\text { ethnic business communities }\end{array}$ & $\begin{array}{l}\text { To explore knowledge sharing behaviour in } \\
\text { established minority ethnic business communities } \\
\text { To explore formal and informal mechanisms by } \\
\text { which new arrivals are introduced to business in } \\
\text { the post-migratory country context }\end{array}$ \\
\hline 3 & $\begin{array}{l}\text { Founding and next generation } \\
\text { aspirations for the 'family business' }\end{array}$ & $\begin{array}{l}\text { To explore the extent to which the foundations of } \\
\text { a family-lead business is a response to limited } \\
\text { options following migration } \\
\text { To explore whether founders perceive the } \\
\text { business as an early-stage family business } \\
\text { To explore succession aspirations within the } \\
\text { founding and next generations }\end{array}$ \\
\hline 4 & $\begin{array}{l}\text { Business support service availability } \\
\text { and uptake within family business in } \\
\text { minority community. }\end{array}$ & $\begin{array}{l}\text { To investigate where and on what basis minority } \\
\text { ethnic businesses seek formal contact with } \\
\text { business support services } \\
\text { To identify barriers to service uptake amongst } \\
\text { minority ethnic family businesses } \\
\text { To explore advisor perceptions of the provision } \\
\text { of business support services for a variety of } \\
\text { community and cultures }\end{array}$ \\
\hline 5 & $\begin{array}{l}\text { The links between culture and family } \\
\text { business in country-of-origin and } \\
\text { new-country }\end{array}$ & $\begin{array}{l}\text { To explore the culture of business behaviour in } \\
\text { pre- and post-migratory country of residence } \\
\text { To explore whether links between business } \\
\text { behaviour in pre- and post-migratory country of } \\
\text { residence are stronger where a family and } \\
\text { existing business continue to operate in the pre- } \\
\text { migratory country }\end{array}$ \\
\hline
\end{tabular}

\section{References}


Baxter-Reid, H. (2016) Buying into the 'Good Worker' Rhetoric or Being as Good as they Need to be? The Effort Bargaining Process of New Migrant Workers. Human Resource Management Journal. 263 337-350

Burrows, R (1990) A Socio-economic Anatomy of the British Petty Bourgeoisie: A Multi-variate Analysis. In: Burrows, R. (ed) (1990) Enterprise Culture: Entrepreneurship, Petty Capitalism and the Re-structuring of Britain. Routledge, London

Burrows, R. (1991) Who Are the Contemporary British Petty Bourgeoisie. International Small Business Journal 92 12-25

Dibrell, C. and Memili, E. (2018) A Brief History and a Look to the Future of Family Business Heterogeneity. An Introduction. p1-2 In: The Palgrave Handbook of Heterogeneity Among Family Firms. Ed. Esra Memili and Clay Dibrell. Palgrave Macmillan, Springer Nature Switzerland, Cham, Switzerland

Dhaliwal, S. (2012) Making a Fortune: Learning from the Asian Phenomenon. John Wiley and Sons, New York

Donato, K. (1992) Understanding US Immigration: Why Some Countries Send Women and Others Send Men." In Seeking Common Ground: Multidisciplinary Studies of Immigrant Women in the United States, edited by Donna Gabaccia. New York: Greenwood Press, 1992.

Gabaccia, Donna, Katherine Donato, Jennifer Holdaway, Martin Manalansan, and Patricia Pessar, eds. (2006) International Migration Review. Special issue on "Gender and Migration." Vol. 40

Greenwood, M. J. and Hunt, G. L. (2003) The Early History Of Migration Research International Regional Science Review 261 3-37 DOI 10.1177/0160017602238983

Immigration History Research Centre (2015) Gender Ratios in Global Migration: Men who Migrate, Women who Wait?

https://cla.umn.edu/ihrc/news-events/other/gender-ratios-global-migration-men-who-migrate-women-

who-wait June 24th 2015

Mohr, S. and Berendes, H. (2018) Founders Human Capital and Vision as Determining Factors for the Choice of Leadership Style and Employees in New Ventures. Masters Thesis, Jönköping International Business School. ISRN JU-IHH-GMT-2-20180043

Oishi, N. (2005) Women in Motion: Globalization, State Policies and Labor Migration in Asia. Stanford: Stanford University Press, 2005.

Ram, M. and Holliday, R. (1993) Relative Merits: Family Culture and Kinship in Small Firms. Sociology $274693-648$

Rainnie, A. (1989) Industrial Relations in Small Firms: Small Isn’t Beautiful. Routledge, London

Rainnie, A. (1990) Small Firms: Between the Enterprise Culture and New Times. In: Burrows, R, (ed) (1990) Enterprise Culture: Entrepreneurship, Petty Capitalism and the Re-structuring of Britain. Routledge, London

Ravenstein, E.G. "The Laws of Migration." Journal of the Statistical Society of London. Vol 48, N. 2 (June, 1885): 196-199 
Ritchie, J. (1990) Enterprise Cultures: A Frame Analysis. In: Burrows, R, (ed) (1990) Enterprise Culture: Entrepreneurship, Petty Capitalism and the Re-structuring of Britain. Routledge, London

Riva, A. and Pilotti, L. (2018) Community Vision and Strategic Decisions: The Case of City of Portland in Region of Oregon (U.S.A.). Journal of Business and Economic Policy 5 1 37-46

Scase, A. (1982) The Petty Bourgeoisie and Modern Capitalism: A Consideration of Recent Theories. In: Giddens, A. and Mackenzie, G. (eds) (1982) Social Class and the Division of Labour. Cambridge University Press, Cambridge.

Seaman, C., Bent, R. Unis, A. (2015) The Future of Family Entrepreneurship: Family Culture, Education and Entrepreneurial Intent in Scottish Pakistani Communities. Futures. Special Issue on the Futures of Family Entrepreneurship. Editors: Randerson, K., Fayolle, A. and Bettinelli, C. http://www.sciencedirect.com/science/article/pii/S0016328715300458

Vershinina, N., Barrett, R., and Meyer, M. (2011) Forms of Capital, Intra-ethnic variation and Polish Entrepreneurs in Leicester. Work, Employment and Society. 251 101-117 